\title{
Melatonin reduces ultraviolet- $B$ induced cell damages and polyamine levels in human skin fibroblasts in culture
}

\author{
Kyu-Suk Lee $e^{1,5}$, Won-Suk Lee ${ }^{1}$, \\ Seong-ll Suh ${ }^{2}$, Sang-Pyo Kim ${ }^{3}$, \\ Sung-Ryong Lee ${ }^{4}$, Young-Wook Ryoo ${ }^{1}$, \\ and Byung-Chun Kim ${ }^{1}$ \\ ${ }^{1}$ Institute of Medical Science and \\ Department of Dermatology \\ ${ }^{2}$ Department of Microbiology \\ ${ }^{3}$ Department of Pathology \\ ${ }^{4}$ Department of Pharmacology \\ School of Medicine, Keimyung University, Daegu 700-120, Korea \\ ${ }^{5}$ Corresponding author: Tel, 82-53-250-7624; \\ Fax, 82-53-250-7626; E-mail, franzes@dsmc.or.kr
}

Accepted 2 June 2003

Abbreviations: GAPDH, glyceraldehyde-3-phosphate dehydrogenase; ODC, ornithine decarboxylase

\begin{abstract}
UV radiation is known to cause photoaging of the skin and is considered one of the leading cause of developing skin carcinogenesis. Melatonin which has a highly lipophilic molecular structure facilitating penetration of cell membranes and serving as an extra- and intracellular free radical scavenger has been demonstrated to protect photodamage of skin affected by UV exposure. In this study, we have examined the role of melatonin in response to UVB induced photodamaging process, using human skin fibroblasts in vitro. Cell survival curves after UVB irradiation showed dose-dependent decrease. Only $60 \%$ of fibroblasts were survived at $140 \mathrm{~mJ} / \mathrm{cm}^{2}$ UVB irradiation. By pre-cultivation of cells with melatonin $(100 \mathrm{nM})$, a significant number of cells remained unaffected. After UVB irradiation with $70 \mathrm{~mJ} / \mathrm{cm}^{2}$, the level of putrescine was $1.7 \pm 0.3$ fold increased compared to melatonin pre-treated group. In Northern analyses, the transcriptional level of ornithine decarboxylase (ODC) gene expression was increased by UVB irradiation and prohibited by melatonin. These results indicated that melatonin was effectively able to neutralize membrane peroxidation when present in relevant concentration during UVB irradiation and diminishes the UVB-induced increase of poly-
\end{abstract}

amine synthesis and ODC gene expression. Collectively, ODC response to UVB induced changes are possibly involves a melatonin or antioxidant sensitive regulatory pathway in normal human skin fibroblast.

Keywords: antioxidants; cell death; melatonin; ornithine decarboxylase; polyamine; ultraviolet rays

\section{Introduction}

Exposure to UV results in photoaging of the skin and is considered an initiating event of skin carcinogenesis (Chainiaux et al., 2002). UVB radiation not only causes inducing DNA damage and cell mutagenecity, but can also modulate the expression of several genes at dose levels to natural solar exposure (Shindo and Hashimoto, 1998). Some of these genes are regulated by an oxidative mechanism (Lee et al., 1998; Takeda et al., 2002). It has been reported that the effect of UVB radiation on the in vitro regulation of important enzymes that participate in inflammation and cancer progression (Kulms et al., 2002). The polyamines, (putrescine, spermidine, and spermine) have been shown to be essential for mammalian cell growth and function (Ahmad et al., 2001). Intracellular polyamine concentrations are highly regulated by the enzyme, ornithine decarboxylase (ODC), which catalyzes the conversion of ornithine to putrescine, the initial and often rate limiting step in polyamine biosynthesis (van Weelden et al., 1990; O'Brien et al., 1997). UVB light induces overexpression of ODC an enzyme that plays a critical role in photocarcinogenesis (Jansen et al., 2001). Therefore, the ODC activity served as a marker of the mutagenic and carcinogenic effects of UV light, because the activity of ODC in quiescent cells is extremely low and readily induced by UV light (Manzow et al., 2000). Furthermore, ODC is also activated by many other stimuli including tumor promoters and growth factors (Oguro and Yoshida, 2001), as well. Melatonin (N-acetyl5-methoxytrptamine) is a hormone with multiple functions in human, produced by the pineal gland and stimulated by beta-adrenergic receptors (Ryoo et al., 2001). Areas of greater interest and potential importance include the antimitotic effects of melatonin on some types of tumor cells in culture and potent radical scavenging effects, but there has been little progress toward identifying the specific mechanisms 
of its action. In the present study, we investigated whether the photoprotective actions of melatonin can attenuate the changes of polyamine levels following UVB induced cell damages in cultured skin fibroblasts.

\section{Materials and Methods}

\section{Fibroblast culture}

Primary cultures of dermal fibroblasts were established from children $(n=3$, mean age $=5 \mathrm{yr}$ ) skin left over from cosmetic surgery and cultured on plastic culture dishes in DMEM supplemented with $10 \%$ FBS, penicillin $(100 \mathrm{U} / \mathrm{ml})$, streptomycin $(100 \mu \mathrm{g} / \mathrm{ml})$, and amphotericin B $(1 \mu \mathrm{g} / \mathrm{ml})$. The cells were maintained in a humidified $5 \% \mathrm{CO}_{2}, 95 \%$ air incubator at $37^{\circ} \mathrm{C}$. Analyses of confluent fibroblast cultures were carried out at 3-6 passages of subcultivation, $1 \times 10^{5} / \mathrm{ml}$. Cell viability was determined by trypan blue exclusion.

\section{UVB irradiation}

Immediately before irradiation, the medium was replaced by PBS. UVB was supplied by a closely spaced array of seven Westinghouse FS-40 sunlamps, which delivered uniform irradiation at a distance of $30 \mathrm{~cm}$. The energy output of UVB (290-320 $\mathrm{nm}$ ) was measured with a UVB photometer (IL 1350 photometer, International Light, Mass). The output of the FS-40 sunlamps was $0.1 \mathrm{~mW} / \mathrm{cm}^{2}$ at $38 \mathrm{~cm}$. UVB irradiation doses were $0,50,70,140$, and $200 \mathrm{~mJ} /$ $\mathrm{cm}^{2}$.

\section{Melatonin treatment}

Melatonin was purchased from Sigma (St Louis, MO) and dissolved in $95 \%$ ethanol. We treated cultured fibroblasts with 10-1,000 nM melatonin $3 \mathrm{~min}$ before UV irradiation and after UV irradiation for $24 \mathrm{~h}$.

\section{Propidium iodide staining}

After 2 or 5 days of culture, the cells were fixed with $4 \%$ paraformaldehyde in $0.1 \%$ PBS $(\mathrm{pH} \mathrm{7.4)}$ for 10 $\mathrm{min}$ at room temperature, followed by $70 \%$ ethanol containing $1 \% \mathrm{HCl}$ for $10 \mathrm{~min}$ at $-20^{\circ} \mathrm{C}$, and then stained with $1 \mathrm{~g} / \mathrm{ml}$ propidium iodide containing 100 $\mu \mathrm{g} / \mathrm{ml}$ DNAase free RNase A for $30 \mathrm{~min}$ at $37^{\circ} \mathrm{C}$ to visualize the nuclei. The cells were examined with a confocal laser scanning microscopy. More than 100 cells in several microscopic fields were counted under the microscope to determine the percentage of apoptotic cells.

\section{Polyamine extraction and HPLC analysis}

The extraction procedure was carried out in ice-chilled conditions. Derivation and HPLC analysis of polyamines were based upon the methods of Spragg and Hutchings (1983) with some modification. Each cultured cells were lysed in 10 volumes of ice-chilled 0.4 $\mathrm{M}$ perchloric acid containing $2 \mathrm{mM}$ EDTA and $40 \mu \mathrm{M}$ 1,8-diaminooctane as an internal standard. And centrifuged at $15,000 \mathrm{~g}$ for $10 \mathrm{~min}$, at $4^{\circ} \mathrm{C} .200 \mu \mathrm{l}$ of the supernatant was evaporated by a vacuum drier. The dried samples were dissolved in $100 \mu \mathrm{l}$ of $1 \mathrm{M}$ sodium bicarbonate then derived with $300 \mu$ of 4 fluoro-3-nitrobenzo-trifluoride (FNBT) reagent (a mixture of $10 \mu \mathrm{l}$ of FNBT and $1 \mathrm{ml}$ of DMSO at $60^{\circ} \mathrm{C}$ for $20 \mathrm{~min}$. At the end of derivation, $40 \mu \mathrm{l}$ of $1 \mathrm{M}$ histidine in $1 \mathrm{M}$ sodium bicarbonate was added to the reaction mixture then the derivation continued for another $5 \mathrm{~min}$ to scavenge excess FNBT. After cooling the mixture in an ice basket, the N-2-nitro-4trifluoromethylphenyl derivatives of polyamines were extracted twice with $2 \mathrm{ml}$ of 2-methylbutane. After centrifugation at $3,000 \mathrm{~g}$ for $10 \mathrm{~min}$, the organic phase was evaporated under nitrogen gas flow and the residue was reconstituted with $1 \mathrm{ml}$ of HPLC grade methanol. The $20 \mu$ of the methanol solution was applied to the isocratic reversed phase HPLC system (Gilson Medical Electronics, Villiers-le-Bel, France), then the separation of NTP-polyamines was accomplished by elution of acetonitrile-water (85:15, $\mathrm{v} / \mathrm{v}$ ) mobile phase at the flow rate of $1.0 \mathrm{ml} / \mathrm{min}$ within $30 \mathrm{~min}$. The eluent was monitored by UVIVIS detector set at $242 \mathrm{~nm}$ and a MicrosorbTM C18 column (5 $\mathrm{M}, 4.6 \mathrm{~mm}, 25 \mathrm{~cm}$, Rainin instrument Co., Woburn, Mass) was used.

\section{cDNA probe preparation}

The following human-sequence-specific cDNAs were utilized in this study: a $3.2 \mathrm{~kb}$ cDNA for ODC; a 1.2 $\mathrm{kb}$ cDNA for GAPDH. The cDNAs were labeled with $\left[{ }^{32} \mathrm{P}\right]$-dCTP (NEG 036H, New England Nuclear, USA) by nick translation (Rigby et al., 1977) to a specific activity of approximately $1 \times 10^{8} \mathrm{cpm} / \mu \mathrm{g}$.

\section{Quantitation of mRNA levels by Northern blot analysis}

Total RNA was isolated by the methods of Chomzynski and Sacchi (1987) from cultured normal skin fibroblasts. Total RNA $(20 \mu \mathrm{g})$ was fractionated by $1 \%$ agarose gel electrophoresis (85 V, $5 \mathrm{~h}$ ) after denaturating the samples with formaldehyde and formamide (Wahl et al., 1979). RNA transcripts obtained were transferred to the charged nylon filter (Zetaprobe, BioRad, CA) in $20 \times S S C$ overnight at $4{ }^{\circ} \mathrm{C}$ (Theiss et al., 2002). The filters was prehybridized for 
$12-18 \mathrm{~h}$ at $42^{\circ} \mathrm{C}$ with prehybridization mixture $(50 \%$ formamide, $0.1 \%$ SDS, $3 \times$ SSC, $1 \times$ Denhart's solution, $50 \mathrm{~g} / \mathrm{ml}$ ss-DNA) and hybridized with $\left[{ }^{32} \mathrm{P}\right]$ labeled $\mathrm{CDNA}$ by nick translation at $42^{\circ} \mathrm{C}$ for 24 to $36 \mathrm{~h}$. Following hybridization, the filters were washed and autoradiography was performed.

\section{Results}

\section{UVB induced cytotoxicity and melatonin defense}

To examine the effect of UVB irradiation, cultured dermal fibroblasts were exposed to varying doses of UVB $50,70,140$, and $200 \mathrm{~mJ} / \mathrm{cm}^{2}$ and checked their cell viability after $24 \mathrm{~h}$ later. Such treatment result in $80 \pm 9.2 \%, \quad 56 \pm 6.9 \%, \quad 43 \pm 5.2 \%, \quad 26 \pm 5.8 \%$ of surviving cells, respectively (Figure 1). To clarify the effect of melatonin on dermal fibroblasts under UVB irradiation $\left(140 \mathrm{~mJ} / \mathrm{cm}^{2}\right)$, we treated with $10-1000 \mathrm{nM}$ of melatonin. The protective effect was obtained from $1 \mu \mathrm{M}$ and $100 \mathrm{nM}$ of melatonin, the cell viability in the pre-treated groups with $1 \mu \mathrm{M}$ and $100 \mathrm{nM}$ of melatonin were $58 \%$ and $64.5 \%$, respectively. The pre-treated groups with $100 \mathrm{nM}$ of melatonin are significantly different from only UVB $140 \mathrm{~mJ} / \mathrm{cm}^{2}$ irradiated groups at $P<0.01$ (Figure 2).

\section{Apoptotic changes by UVB irradiation and melatonin defense}

When cells were stained with propidium iodide and observed under confocal laser scanning microscopy, normal cells appear as homogenous fluorescent with oval nuclei. Using this staining method, we found that the UVB irradiated cells were irregular shaped with intensely fluorescent and contained fragmented round bodies characteristics of apoptotic cells after $24 \mathrm{~h}$

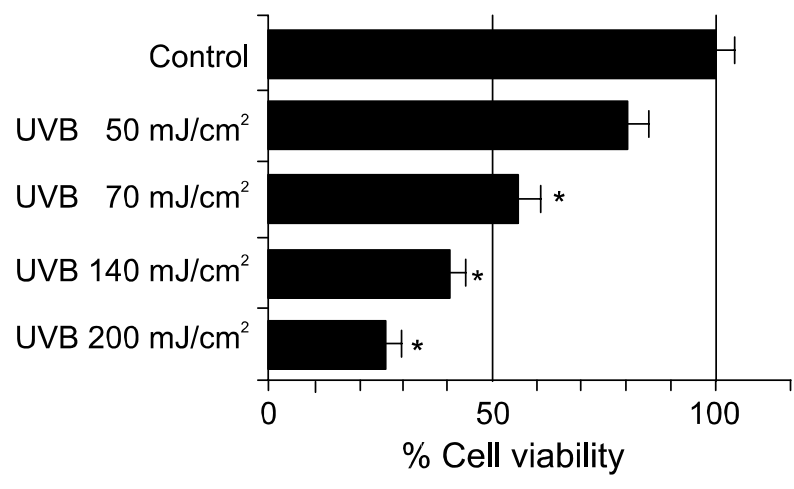

Figure 1. Viability of the dermal fibroblast following UVB treatment. The cells were treated with UVB $\left(50,70,140\right.$ and $\left.200 \mathrm{~mJ} / \mathrm{cm}^{2}\right)$ and the number of viable cells was countered by trypan blue exclusion assay. Data shown are mean values \pm standard errors determined from three independent experiments. ${ }^{*} P<0.01$. after treatment (Figure 3). The degree of apoptosis induced by UVB irradiation and the protective effects of melatonin were measured by counting the number of apoptotic cells among 10 high power field $(\times 400)$. More apoptotic cells were observed in UVB irradiated group than melatonin treated group. The percentage of apoptotic cells in UVB treated group was $35.1 \pm$ $8.21 \%$, whereas those in melatonin protected group was $10.4 \pm 5.95 \%$. In control group, less than $2 \%$ of attached cells showed apoptotic features.

\section{Effects of UVB and melatonin on polyamine level}

The changes in polyamine level were examined 24 $h$ after UVB and melatonin treatment by HPLC analysis. The level of putrescine of UVB irradiated

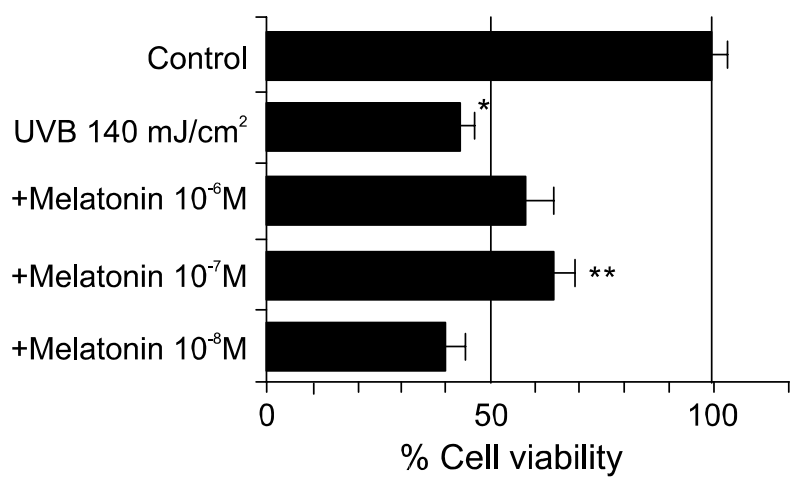

Figure 2. The effects of melatonin on cultured skin fibroblast viability under UVB irradiation $\left(140 \mathrm{~mJ} / \mathrm{cm}^{2}\right)$. Cell viability is represent as percent viable cells, where the untreated cells are regarded as $100 \%$. ${ }^{*}$ Significantly different from control and ${ }^{* *}$ significantly different from only UVB $140 \mathrm{~mJ} / \mathrm{cm}^{2}$ irradiated groups at $P<0.01$.
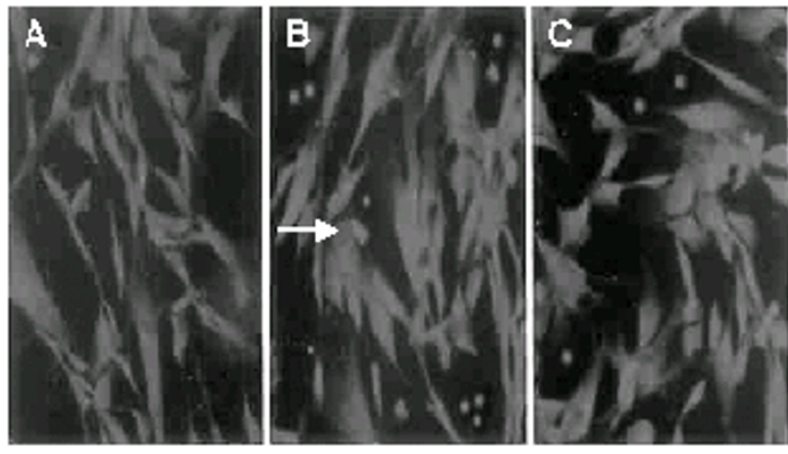

Figure 3. Detection of apoptotic cells by propidium iodide among adherent dermal fibroblasts treated with UVB and/or melatonin. A: untreated control, B: UVB $\left(140 \mathrm{~mJ} / \mathrm{cm}^{2}\right)$ irradiation, C: cells pretreated with melatonin before UVB irradiation and incubated for $24 \mathrm{~h}$ in DMEM containing melatonin $\left(10^{-7} \mathrm{M}\right)$. Apoptotic cells appear in $B$ as condensed, brightly fluorescent, oval particles (arrow) that are easily distinguished from the controls $(A)$ and these changes were moderately protected by melatonin $(\mathrm{C})$. 


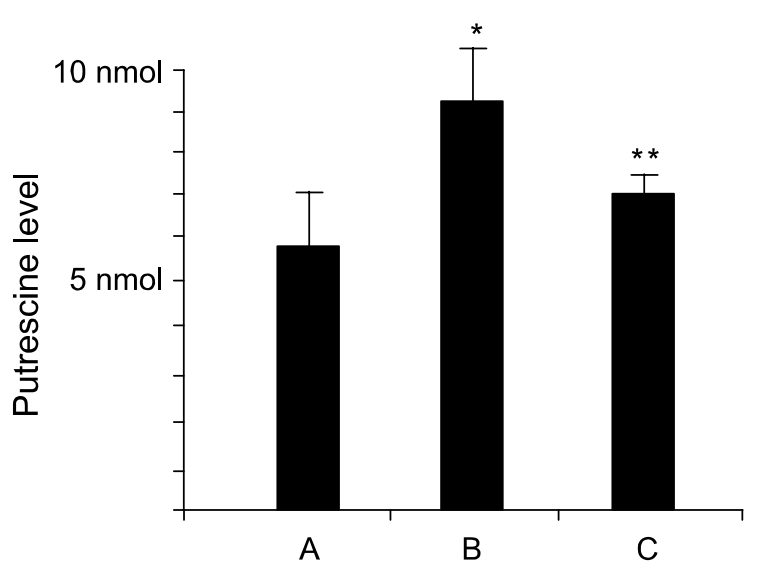

Figure 4. Quantitation of putrescine levels under UVB and melatonin by HPLC. A, control; B, UVB $140 \mathrm{~mJ} / \mathrm{cm}^{2} ;$ C, UVB $140 \mathrm{~mJ} / \mathrm{cm}^{2}+$ melatonin $10^{-7} \mathrm{M}$. Data are expressed as mean $\pm S D$ of three independent experiments. "Significantly different from control and ** significantly different from only UVB $140 \mathrm{~mJ} / \mathrm{cm}^{2}$ irradiated groups at $P<0.01$.

group was $9.0 \pm 0.79 \mathrm{nmol}$ per $\mathrm{ml}$ which was increased compared to the untreated control $(5.2 \pm 0.44$ $\mathrm{nmol})$. When pre-treated with melatonin before UVB irradiation, the level of putrescine was $6.9 \pm 0.55 \mathrm{nmol}$ (Figure 4).

\section{Expression of ODC gene}

In northern blot analysis of cultured normal skin fibroblasts, $\left.{ }^{32} \mathrm{P}\right]$-labeled ODC and GAPDH CDNA probes specifically hybridized with each mRNA. ODC revealed $9.0 \mathrm{~kb}$ sized mRNA transcript, while GAPDH revealed $1.3 \mathrm{~kb}$. There were no changes in size, indicating no alteration in quality. Northern analysis with CDNA probe for ODC after UVB $(70,140 \mathrm{~mJ} /$ $\mathrm{cm}^{2}$ ) irradiation resulted in a signal markedly increased (by about $1.7 \pm 0.07,2.2 \pm 0.79$ folds respectively) compared to control, after correction of the signal by GAPDH mRNA levels. And these over-expressions were decreased up to $1.4 \pm 0.06$, and 1.45 \pm 0.02 folds under melatonin pretreatment at concentration of $100 \mathrm{nM}$ compared to control. This means melatonin pretreatment decreased UVB induced ODC mRNA levels up to $35 \%$ (Figure 5). Relative quantitation of ODC mRNA levels were measured, where the untreated cells are regarded as 100 densitometric absorbance units (Table 1).

\section{Discussion}

Polyamines are present in living cells and play a pivotal role in cellular growth and developmental process (Theiss et al., 2002). The naturally occurring polya-

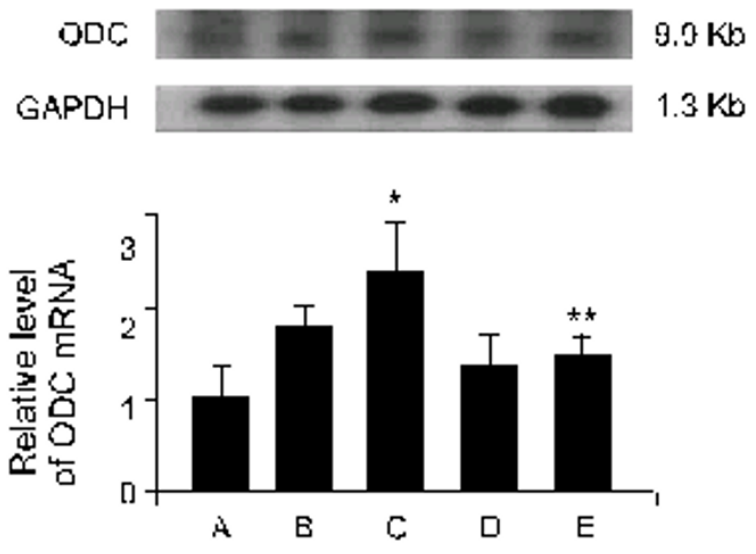

Figure 5. Quantitation of ODC gene expression by northern blot analyses, where the untreated cells are regarded as 100 densitometric absorbance unit (DAU). A, Control; B, C, UVB 70/140 mJ/cm²; D, E, UVB $70 / 140 \mathrm{~mJ} / \mathrm{cm}^{2}+$ melatonin $10^{-7} \mathrm{M}$. Data are expressed as mean \pm SD of three independent experiments. "Significantly different from control and ${ }^{* *}$ significantly different from only UVB $140 \mathrm{~mJ} / \mathrm{cm}^{2}$ irradiated groups at $P<0.01$.

Table 1. Steadv-state levels of ODC mRNA.

$\begin{array}{lrl}\text { Control } & 49 \pm 9(1) \\ \text { UVB } 70 \mathrm{~mJ} / \mathrm{cm}^{2} & 83 \pm 8(1.7) \\ \text { UVB } 140 \mathrm{~mJ} / \mathrm{cm}^{2} & 110 \pm 11(2.25) \\ \text { UVB } 70 \mathrm{~mJ}+\text { Melatonin } 10^{-7} \mathrm{M} & 68 \pm 9(1.4) \\ \text { UVB } 140 \mathrm{~mJ}+\text { Melatonin } 10^{-7} \mathrm{M} & 71 \pm 6(1.45)\end{array}$

The values are mean $\pm S D$ and expressed as densitometric absorbance unit which are the percentage of the value of GAPDH. Fold difference is shown in parethesis, *Significantly different from control and ${ }^{* *}$ significantly different from only UVB $140 \mathrm{~mJ} / \mathrm{cm}^{2}$ irradiated groups at $P<0.01$

mines in mammamlian cells are putrescine, spermidine, and spermine (Megosh et al., 2002). ODC plays a critical role in the biosynthesis of those polyamines (Rebel et al., 2002). Actually, the level of ODC activity in quiescent cells is extremely low, but readily induced by a wide variety of growth-promoting agents or UV light (Nilsson et al., 2000; Tanaka et al., 2001). Also rapidly proliferating cells and neoplastic cells express elevated levels of ODC, therefore the level of ODC activity is served as a marker of the initial mutagenic and carcinogenic process. Ultraviolet radiation activates the expression of a wide variety of genes by pathways which differ between the short non-solar UVC wavelengths, which are strongly absorbed by nucleic acids, and the long solar UVA (320-380 nm) wavelengths, which generate active oxygen intermediates. Intermediate solar UV wavelengths in the UVB (290-320 nm) range also contain 
an oxidative component, but also closely resemble UVC in their gene activating properties. Short wavelength UV, in common with other extracellular stimuli including growth factors, activates signal transduction events that involve both stress- and mitogen-activated protein kinase cascades (Reeve et al., 2000; Soriani et al., 2000; Tyrrell, 2000; Kim et al., 2001). This study describes the protective effects of melatonin in skin fibroblast against the UVB induced apoptotic changes. UVB induced cytotoxicity was examined 24 $\mathrm{h}$ after treatment by trypan blue exclusion test. A distinct dose response relationship was observed between the dose of UVB and the degree of survival rate. About $26 \%$ of cultured dermal fibroblasts were only survived at $200 \mathrm{~mJ} / \mathrm{cm}^{2}$. The UVB induced cytotoxicity is a rapid event, and melatonin prevents such damage when present at concentration of $1 \mathrm{nM}$ (Fischer et al., 1999). In our study, the protective effect of melatonin was observed at concentration of $1 \mu \mathrm{M}$ and $100 \mathrm{nM}$. This discrepancy may result from different proctocol (in vivo vs in vitro). Moreover, melatonin treated cells showed marked suppression of UVB induced apoptotic changes. Like the other methods, this one also has some limitations in that it does not include all the floating cells. Therefore, these values are an underestimation of the actual degree of apoptosis. It was our interest to know whether the photoprotective actions of melatonin can attenuate the changes of polyamine levels and ODC activities following UVB irradiation in cultured skin fibroblasts. Putrescine is the first product from ornithine by the action of ODC and known as a marker of cell injury. The level of putrescine of UVB irradiated group was 1.7 times increased compared to the untreated control. When pre-treated with melatonin before UVB irradiation, the level of putrescine was decreased up to $75 \%$. The expression of ODC gene after UVB irradiation resulted in markedly increased with dose dependent fashion. This result is supported by other previous reports (Bornman et al., 1999; Soriani et al., 1999). And these overexpressions were decreased up to $65 \%$ under melatonin pretreatment at concentration of $100 \mathrm{nM}$. The suppressive effect of melatonin to increased ODC mRNA can be resulted from increasing turn-over time of mRNA or decreasing transcription. Additionally, that effect of melatonin may be related with role of melatonin as antioxidant or not. Therefore, to elucidate the mechanisms of action of melatonin to polyamine and ODC gene, further experiments are needed. In conclusion, our results demonstrate that melatonin not only directly acts as a protector from cell damage induced by UVB irradiation only when present in relevant concentration at the site of action beginning but diminishes the UVB induced increase of polyamine synthesis and ODC gene expression. Collectively, ODC response to UVB induced changes are possibly involves melatonin sensitive regulatory pathway in normal human skin fibroblast.

\section{Acknowledgement}

The present research has been supported by the Attached Research Institute Research Grant of Keimyung University in 2001.

\section{References}

Ahmad N, Gilliam AC, Katiyar SK, O'Brien TG, Mukhtar H. A definitive role of ornithine decarboxylase in photocarcinogenesis. Am J Pathol 2001;159:885-92

Bornman L, Baladi S, Richard MJ, Tyrrell RM, Polla BS. Differential regulation and expression of stress proteins and ferritin in human monocytes. J Cell Physiol 1999;178:1-8

Chainiaux F, Magalhaes J, Eliaers F, Remacle J, Toussaint $O$. UVB-induced premature senescence of human diploid skin fibroblasts Int J Biochem Cell Biol 2002;34:1331-4

Chomczynski $P$, Sacchi N. Single-step method of RNA isolation by acid guanidium thiocyanate-phenol-chloroform extract. Anal Biochem 1987;162:156-9

Fischer T, Bangha E, Elsner P, Kistler GS. Suppression of UV-induced erythema by topical treatment with melatonin. Influence of the application time point. Biol Signals Recept 1999;8:132-5

Jansen AP, Dreckschmidt NE, Verwiebe EG, Wheeler DL, Oberley TD, Verma AK. Relation of the induction of epidermal ornithine decarboxylase and hyperplasia to the different skin tumor-promotion susceptibilities of protein kinase $\mathrm{C}$ alpha, -delta and -epsilon transgenic mice. Int $\mathrm{J}$ Cancer 2001;93:635-43

Kim BC, Shon BS, Ryoo YW, Kim SP, Lee KS. Melatonin reduces $X$-ray irradiation-induced oxidative damages in cultured human skin fibroblasts. J Dermatol Sci 2001;26:194200

Kulms D, Zeise E, Poppelmann B, Schwarz T. DNA damage, death receptor activation and reactive oxygen species contribute to ultraviolet radiation-induced apoptosis in an essential and independent way. Oncogene 2002;29:5844-51

Lee KS, Kim SJ, Ryoo YW, Kim BC. All-trans-retinoic acid down-regulates elastin promoter activity elevated by ultraviolet $B$ irradiation in cultured skin fibroblasts. J Dermatol Sci 1998;17:182-9

Manzow S, Richter KH, Stempka L, Furstenberger G, Marks $F$. Evidence against a role of general protein kinase $C$ downregulation in skin tumor promotion. Int J Cancer 2000;85:503-7

Megosh LC, Hu J, George K, O'Brien TG. Genetic control of polyamine-dependent susceptibility to skin tumorigenesis. Genomics 2002;79:505-12

Nilsson J, Gritli-Linde A, Heby O. Skin fibroblasts from spermine synthase-deficient hemizygous gyro male (Gy/Y) mice overproduce spermidine and exhibit increased resistance to 
oxidative stress but decreased resitance to UV irradiation. Biochem J 2000;352:381-7

O'Brien TG, Megosh LC, Gilliard G, Soler AP. Ornithine decarboxylase overexpression is a sufficient condition for tumor promotion in mouse skin. Cancer Res 1997;57:2630-7

Oguro T, Yoshida T. Effect of ultraviolet $A$ on ornithine decarboxylase and metallothionein gene expression in mouse skin. Photodermatol Photoimmunol Photomed 2001;17:71-8

Rebel $H$, van Steeg $H$, Beems RB, Schouten R, de Gruijl FR, Terleth C. Suppression of UV carcinogenesis by difluoromethylornithine in nucleotide excision repair-deficient Xpa knockout mice. Cancer Res 2002;62:1338-42

Reeve VE, Tyrrell RM, Shen J. Interactions between the UVA and UVB wavebands relevant for immune function and carcinogenesis. Redox Rep 2000;5:50-1

Rigby PW, Dieckmann M, Rhodes C, Berg P. Labeling deoxyribonucleic acid to high specific in vitro by nick-translation with DNA polymerase I. J Mol Biol 1977;113:237-51

Ryoo YW, Suh SI, Mun KC, Kim BC, Lee KS. The effects of the melatonin on ultraviolet-B irradiated cultured dermal fibroblasts. J Dermatol Sci 2001;27:162-9

Shindo $\mathrm{Y}$, Hashimoto T. Ultraviolet B-induced cell death in four cutaneous cell lines exhibiting different enzymatic antioxidant defences: involvement of apoptosis. J Dermatol Sci 1998;17:140-50

Soriani M, Luscher P, Tyrrell RM. Direct and indirect modulation of ornithine decarboxylase and cyclooxygenase by UVB radiation in human skin cells. Carcinogenesis 1999;20:727-32

Soriani M, Hejmadi V, Tyrrell RM. Modulation of $c$-jun and $c$-fos transcription by UVB and UVA radiations in human dermal fibroblasts and KB cells. Photochem Photobiol 2000; $71: 551-8$
Spragg BP, Hutchings AD. High-performance liquid chromatographic determination of putrescine, spermidine, and spermine after deprivation with 4-fluoro-3-nitroben-zotrifluoride. J Chromatogr 1983;258:289-92

Takeda J, Ito Y, Maeda K, Ozeki Y. Assignment of UVBresponsive cis-element and protoplastization-(dilution-) and elicitor-responsive ones in the promoter region of a carrot phenylalanine ammonia-lyase gene (gDcPAL1). Photochem Photobiol 2002;76:232-8

Tanaka K, Kamiuchi S, Ren Y, Yonemasu R, Ichikawa M, Murai $H$, Yoshino M, Takeuchi S, Saijo M, Nakatsu $Y$, Miyauchi-Hashimoto $\mathrm{H}$, Horio T. UV-induced skin carcinogenesis in xeroderma pigmentosum group A (XPA) geneknockout mice with nucleotide excision repair-deficiency. Mutat Res 2001;477:31-40

Theiss C, Bohley P, Voigt J. Regulation by polyamines of ornithine decarboxylase activity and cell division in the unicellular green alga Chlamydomonas reinhardtii. Plant Physiol 2002;128:1470-9

Tyrrell RM. Role for singlet oxygen in biological effects of ultraviolet A radiation. Methods Enzymol 2000;319:290-6

van Weelden $\mathrm{H}$, van der Putte SC, Toonstra J, van der Leun JC. Ultraviolet B-induced tumors in pigmented hairless mice, with an unsuccessful attempt to induce cutaneous melanoma. Photodermatol Photoimmunol Photomed 1990;7:68-72

Wahl GM, Stern M, Starck GR: Efficient transfer of large DNA fragments from agarose gel to diabenzyloxymethyl-paper and rapid hybridization by using dextran sulfate. Proc Natl Sci USA 1979;76:3683-7 